\title{
Sustainability evaluation of end-of-life vehicle recycling based on emergy analysis: a case study of an end-of-life vehicle recycling enterprise in China
}

\author{
Yuxue Pan, Haitao Li* \\ Key Laboratory of Land Surface Pattern and Simulation, Institute of Geographical Sciences and Natural Resources Research, Chinese Academy of Sciences, \\ Beijing 100101, China
}

\section{A R T I C L E I N F O}

\section{Article history:}

Received 30 September 2015

Received in revised form

30 March 2016

Accepted 6 May 2016

Available online 14 May 2016

\section{Keywords:}

Sustainability

Emergy analysis

End-of-life vehicles

China

\begin{abstract}
A B S T R A C T
As issues concerning "circular economy" and "sustainable development" have been advocated globally, the recycling, reuse, recovery or disposal of end-of-life vehicles (ELVs) have gained more and more attention. Toxic substances and wasted resources within ELVs make evaluating the sustainability of ELV recycling enterprises to be especially important for sound ELV management. In this study, an improved emergy analysis with traditional and revised emergy indices was employed for evaluation of the efficiency and sustainability of ELV recycling enterprises. The constructed emergy indicator system not only reflected the ELV recycling system's resource, environmental, economic and technological efficiency, but also made a multi-scale and multi-dimensional evaluation of the system according to its industrial characteristics. An ELV recycling enterprise in Jiangxi Province, China, as a case, was studied employing the proposed method and indicator system. The results showed that the enterprise involved in the study had strong competitive ability with relatively high economic benefit, and had a moderate environmental impact compared with other industrial systems. The emergy sustainability index indicated that the recycling enterprise was both economically and environmentally sustainable in the long term. However, the emergy technical efficiency indices indicated that the technical level and operational efficiency of the ELV recycling enterprise were relatively low and more investment should be put into the improvement of the recycling technologies. The results of the study can provide useful information for the decision makers to manage ELV recycling enterprises considering not only economic benefits but also the environmental benefits in the long term.
\end{abstract}

(c) 2016 Elsevier Ltd. All rights reserved.

\section{Introduction}

With an explosive growth of China's automobile industry since 2000, China has become the largest domestic market of vehicles in 2009. The average growth rate of new vehicles in China from 1999 to 2009 was about $22 \%$ (Hu and Kurasaka, 2013). Especially, due to a series of incentive policies which encouraged private car ownership to counteract the depressive effects of the global financial crisis in 2008 , the increasing trend experienced a further boost in 2009 with

\footnotetext{
* Corresponding author. Key Laboratory of Land Surface Pattern and Simulation, Institute of Geographical Sciences and Natural Resources Research, Chinese Academy of Sciences, A11 Datun Avenue, Chaoyang District, Beijing 100101, China. Tel.: +8610 64888996; fax: +86 1084834092.

E-mail address: liht@igsnrr.ac.cn (H. Li).
}

an increasing rate of $45.5 \%$ over the previous year. Fig. 1 shows the annual production and sales of China's vehicles from 2000 to 2014. By the end of 2014, the production of vehicles in China, which is increasing dramatically, has reached as much as 23.7 million, ranking first in the world again. Subsequently, the amount of endof-life vehicles (ELVs) increases with the rising output of vehicles. According to an estimated average vehicle scrappage deadline of 10-15 years, China will see the first vehicle scrappage peak in 2015 (PRWEB, 2015). And by 2020, the annual number of ELVs is expected to reach 13 million (Tian and Chen, 2014; Wang and Chen, 2013).

Meanwhile, as issues on "circular economy" and "sustainable development" have been advocated globally, the recycling, reuse, recovery or disposal of ELVs have gained more and more attention. Vehicles are high-tech products made up of thousands of components, which not only contain a variety of recyclable materials 


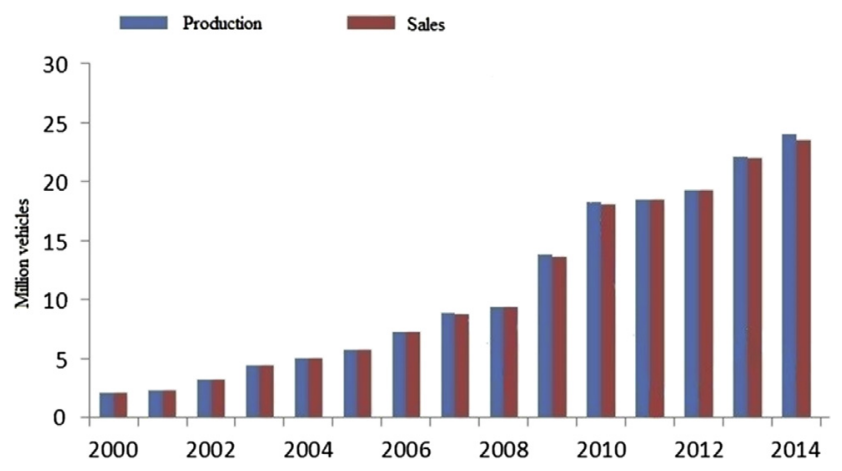

Fig. 1. The annual production and sales of China's vehicles from 2000 to 2014. The blue bars show the annual production of China's vehicles and the red bars show the annual sales of China's vehicles. (For interpretation of the references to colour in this figure legend, the reader is referred to the web version of this article.)

like steel, copper, rubber, etc., but also include different toxic substances such as lubricants, acid solutions, and coolants (Hu and Wen, 2015). According to the experiences of motorized countries such as the US and Japan, improper and informal ELV treatment can cause tremendous and long-term damage to the environment (Zhao and Chen, 2011). Hence, sound ELV management has significance for resource conservation, environmental protection and sustainable development.

Given the toxic substances and wasted resources within ELVs, China has established ELV treatment enterprises to settle the ELV problems. According to the China National Resources Recycling Association, by the end of 2012 there were 522 qualified recycling and dismantling enterprises in China. The number of collection branches was 2,175 , with more than 30,000 employees. However, compared with 337 prefectural - level cities and more than 2000 county-level cities all over the country, the number of qualified recycling and dismantling enterprises was not great enough. Moreover, the "ELV recycling" does not necessarily equal "sustainability", especially when a large number of ELVs flow into the informal enterprises, and subsequently causing adverse effects on the environment and human health (Hu and Wen, 2015). Therefore, it is of great importance to assess the sustainability of ELV recycling enterprises from a systematic point of view, so that all the direct and indirect expenses connected with both human and natural contributions to the ELV recycling process could be accounted for.

Some scholars have carried out relevant researches evaluating the disassemblability of ELV recycling systems using various methods such as spread sheet-like chart (Kroll and Hanft, 1998), end-of-life value (Lee et al., 2001) and time for disassembly (Gungor and Gupta, 1997; Hwa-Cho et al., 2003; Mok et al., 1997). However, few researchers focus on the sustainability of ELV recycling systems and there is no consensus on describing and determining the sustainability of ELV recycling systems. Economy is certainly important for the ELV recycling system of an enterprise to survive, but an economical input-output analysis alone is not sufficient to reveal the environmental effects, nor to achieve cleaner production. Only detailed knowledge of material and energetic flows together with potential technical improvements does this. One relatively new concept, emergy, seems to provide a chance of linking analysis of material and energetic flows by means of defining a common currency. In this study, emergy analysis is first applied to evaluation of ELV recycling systems from the perspective of both economic and environmental benefits.

In the 1980s, emergy analysis was first developed by Odum, who inventively combined the field of energetics with systems ecology. Emergy analysis is superior to energy analysis and economic analysis (Ren et al., 2013). On the one hand, emergy analysis not only accounts for energy quality, but also calculates energy used previously; thus, emergy analysis provides a more feasible approach to assessing different energy carriers' status and position in the universal energy hierarchy (Chun-rong et al., 2010; Zhang et al., 2011a). On the other hand, the method compensates for the incompetency of economic analysis to assess non-market inputs in an objective way. It expresses different forms of energy with a common physical basis, namely, solar emergy, which allows the comparison of all resources on a fair basis (Yang et al., 2011). Therefore, emergy evaluation convincingly can provide valuable information for a deep insight into the sustainability of an ELV treatment system.

So far, we have found few researches evaluating the sustainability of ELV recycling enterprises based on emergy. The purpose of this study is to introduce a new emergy-based evaluation indices to evaluate the efficiency and sustainability of ELV recycling enterprises. Traditional emergy indices do not address emergy associated with waste nor the renewable resources consumption triggered by the economic products inputs. Different from the traditional emergy indices (for instance, in the study of Zhang et al. (2009), $\mathrm{U}=\mathrm{R}+\mathrm{N}+\mathrm{F}$ ), the newly built emergy evaluation indices (where $U=R+N+F+E_{w}$ ), consider the actual characteristics of ELV recycling system itself and the emergy of waste treatment. Interpretation of the results is done with the aid of traditional and revised emergy indices, which provide a new and practical way to help in decision-making in ELV recycling processes.

\section{Methods}

\subsection{Emergy synthesis approach}

Emergy is defined as "all the amount of available energy (or exergy) inputs directly or indirectly required to provide something when the inputs are expressed in units of one type of energy (usually solar energy)" (Odum, 1988). Emergy can be derived as a function of exergy, but it carries a absolutely different meaning and rationale: not all emergy is equal to exergy; that is, if the amount of energy directly and indirectly required to produce a certain item is high (after a process of selection), it means that the item has high emergy and is valuable for the system, regardless of the exergy it potentially carries (Nielsen and Bastianoni, 2007).

The unit of emergy is solar emjoule (sej). Emergy accounting employs the thermodynamic basis for all forms of materials and energy, but converts them into solar equivalents by means of conversion coefficients: transformity. Transformity is defined as the quotient of a product's emergy divided by its energy. Its units are solar emjoule per joule (abbreviated sej/J) (Odum, 1996).

To evaluate complicated systems, emergy accounting can be a useful tool to integrate all the inputs from the human economy and those so-called coming "free" from the environment, so that issues of public policy and environmental management can be analyzed holistically. Nowadays, emergy evaluation has been widely accepted for system evaluation and environmental accounting (Buonocore et al., 2015; Liu et al., 2014, 2015; Pang et al., 2015; Wang et al., 2015; Winfrey and Tilley, 2016; Zhang et al., 2016). An explanation of concepts, principles and applications of emergy are described in detail by Odum (1996) and also by Brown and Ulgiati (2004a).

\subsection{Emergy indices}

An aggregated system diagram of the ELV recycling enterprise for organizing the relationships between components and pathways of energy and material flows was presented in Fig. 2. 


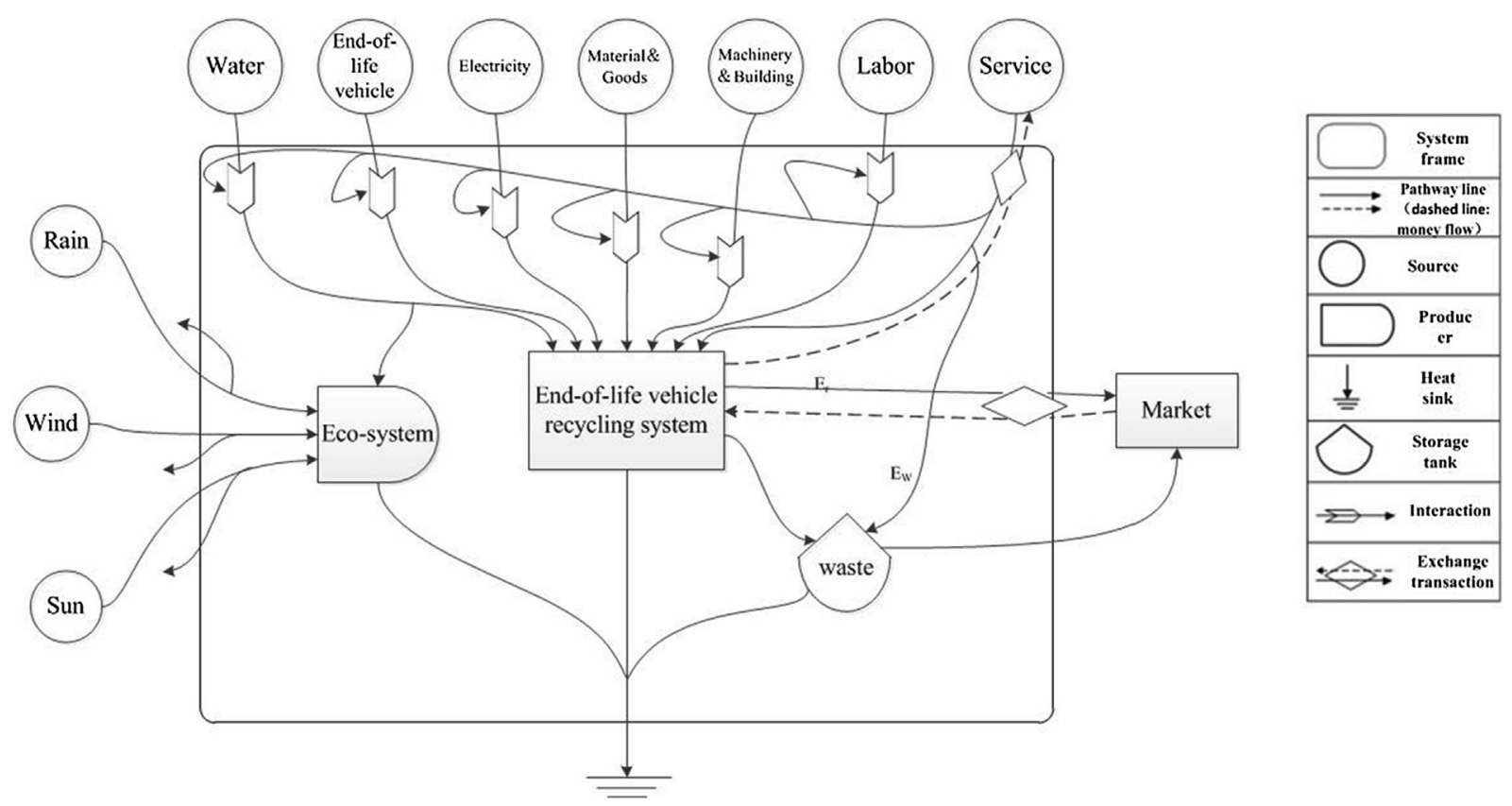

Fig. 2. System diagram of the energy flows in the ELV recycling enterprise.

According to the traditional emergy analysis, the total inputs to the enterprise could be categorized into three types, i.e., nonrenewable resources $(N)$, renewable resources $(R)$ and purchased input $(F)$. The renewable, nonrenewable and purchased emergy constituted the total use of emergy (U), which was defined as the total emergy costs of the yield. Based on the flows illustrated in Fig. 2, emergy indices were calculated and analyzed for an insight into the ELV recycling system and its various performances with regard to sustainability and ecological efficiency.

\subsubsection{The revised emergy indices}

It is noteworthy that the traditional emergy indices are generally rooted in analyzing natural ecological systems. Hence, there are two problems should be concerned when emergy analysis is applied to industrial systems. Firstly, in natural ecological systems, since the wastes of one life form is always the food of some or other life form, it is unnecessary to consider the wastes. But distinguished from natural systems, industrial systems could leave wastes. In an industrial system, no matter the wastes are recycled, reused or directly discharged into the environment, these waste disposal methods all have an effect on the environment and economy, which should be taken into account while evaluating the efficiency and sustainability of industrial systems based on emergy analysis. Traditionally, the emergy of waste management systems, which represents the environmental cost paid for the service of waste treatment, is usually zero (Yang et al., 2003). In this paper, the waste emergy is calculated by the cost of waste disposal on the open market. Secondly, for many industrial systems, compared with the other emergy inputs, the renewable resource emergy $(R)$ is usually negligibly small, resulting in some traditional emergy indices to be unrealistically high or low (Zhang et al., 2009). Besides, most of earlier studies defined only the environmental renewable resources as renewable resources and ignored the "renewable resources" triggered by the recycling progress, for instance, in a waste treatment system, the emergy of recycled waste could be regarded as a kind of renewable resource emergy in some ways; similarly, in an ELV recycling system, the recovery emergy from ELVs is considered as renewable resources.
With respect to the two problems mentioned above, some researchers have made attempts to improve the emergy indices so as to properly evaluate sustainability of industrial systems (Mu et al., 2011; Song et al., 2012, 2013; Zhang et al., 2011b; Zhang et al., 2010). In this paper, the revised emergy indices proposed by Song et al. (2012) were calculated and applied to the sustainability evaluation of an ELV recycling enterprise. Table 1 showed the different expression and explanation of the traditional as well as revised emergy indices.

Total emergy $(U)$ usually measures the renewable $(R)$, nonrenewable $(\mathrm{N})$ and inputs from economy $(\mathrm{F})$ emergy that converge to produce the yield. In the revised emergy analysis, emergy of the service for disposing waste $\left(E_{w}\right)$ is added to the total emergy.

Emergy Intensity (EI) is the ratio of total emergy use in the region to the total area of the region. It measures the amount of input emergy flowing into per unit of area (in units of $\mathrm{sej} / \mathrm{m}^{2}$ ).

The emergy economic efficiency index (EYR) measures the ability of a system to exploit available local resources through investment from the outside. It measures the potential contribution of the system to the main economy, due to the exploitation of local resources. Since the waste emergy is also a kind of investment from the outside, we add $\mathrm{E}_{\mathrm{w}}$ to the denominator.

The emergy environmental efficiency index (ELR) compares the amount $\mathrm{N}$ and $\mathrm{F}$ to the amount of $\mathrm{R}$. It is an indicator of the pressure of the studied system on the environment. It measures the environmental stress due to a production (transformation activity). In the revised $E L R_{\mathrm{r}}, \mathrm{E}_{\mathrm{W}}$ is added to the numerator and can be regarded as a kind of $F$, while $E_{r}$ is considered as renewable resources and added to the denominator.

The emergy sustainability index (ESI) is an aggregated indicator. It is the ratio of EYR and ELR, that is, the ratio of the system's sensibility to the outside-versus-local emergy use and its sensibility to the nonrenewable-versus-renewable emergy use. It measures a system's potential contribution to the economy per unit of environmental loading.

\subsubsection{The technical indices}

To evaluate the technology level of the ELV recycling enterprise, the quotes for emergy recyclability (abbreviation QER) and emergy 
Table 1

Traditional emergy indices and revised emergy indices.

\begin{tabular}{|c|c|c|}
\hline Item & Expression & Explanation \\
\hline Renewable resources & $\mathrm{R}$ & Input emergy of renewable resources \\
\hline Non-renewable & $\mathrm{N}$ & Input emergy of non-renewable resources \\
\hline Input from economy & $\mathrm{F}$ & Input emergy from economy \\
\hline Waste emergy & $\mathrm{E}_{\mathrm{w}}$ & Emergy of the service for disposing waste \\
\hline End-of-life vehicle emergy & $\mathrm{E}_{\mathrm{e}}$ & Emergy of end-of-life vehicle \\
\hline Recycled resource emergy & $\mathrm{E}_{\mathrm{r}}$ & Recovery emergy from end-of-life vehicle \\
\hline \multirow[t]{2}{*}{ Output emergy } & $E_{0}$ & Emergy of all the products \\
\hline & Traditional emergy indices & Revised emergy indices \\
\hline Total emergy & $\mathrm{U}=\mathrm{R}+\mathrm{N}+\mathrm{F}$ & $\mathrm{U}_{\mathrm{r}}=\mathrm{R}+\mathrm{N}+\mathrm{F}+\mathrm{E}_{\mathrm{w}}$ \\
\hline Emergy intensity & $\mathrm{EI}=\mathrm{U} /($ area $)$ & $\mathrm{EI}_{\mathrm{r}}=\mathrm{U}_{\mathrm{r}} /($ area $)$ \\
\hline Emergy economic efficiency index & $\mathrm{EYR}=\mathrm{U} / \mathrm{F}$ & $\mathrm{EYR}_{\mathrm{r}}=\mathrm{U}_{\mathrm{r}} /\left(\mathrm{F}+\mathrm{E}_{\mathrm{w}}\right)$ \\
\hline Emergy environmental efficiency index & $E L R=(F+N) / R$ & $E_{L} R_{r}=\left(F+E_{w}+N\right) /\left(R+E_{r}\right)$ \\
\hline Emergy sustainability index & $\mathrm{ESI}=(\mathrm{EYR}) /(\mathrm{ELR})$ & $\mathrm{ESI}_{\mathrm{r}}=\left(\mathrm{EYR}_{\mathrm{r}}\right) /\left(\mathrm{ELR}_{\mathrm{r}}\right)$ \\
\hline
\end{tabular}

recovery ratio (abbreviation ERR) introduced by Song et al. (2012) were employed.

ERR refers to the quotient of the recycled resource emergy $\left(E_{r}\right)$ divided by the original ELV emergy $\left(\mathrm{E}_{\mathrm{e}}\right)$. The expression of ERR can be represented as follows:

$\mathrm{ERR}=\frac{E_{r}}{E_{e}} \times 100 \%$

The concept of QER comes from the concept of Quotes for Environmentally Weighted Recyclability (QWERTY), which is proposed by Huisman (2003), and then it is developed by Song et al. (2012), who import the concept of emergy recyclability instead of the environmentally weighted recyclability. Thus, QER can be calculated as follows:

$\mathrm{QER}=\frac{E_{a}-E_{\min }}{E_{\max }-E_{\min }} \times 100 \%$

where $E_{\max }$ represents the maximum emergy recyclability and is calculated when all materials are recycled with no consumption of emergy paid for transferring the left resources to a landfill. $E_{\min }$ represents the minimum value of emergy recyclability, calculated when no material is recycled and all the ELVs are regarded as hazardous waste transferred to landfills. $E_{a}$ represents the actual emergy recyclability of the ELV recycling enterprise.

The equation of the maximum emergy recyclability can be calculated as follows:

$E_{\max }=E_{r}^{\prime}-E_{c}^{\prime}$

where $E_{r}^{\prime}$ represents the recycled resource emergy in the best case; $E_{c}^{\prime}$ represents the consumption emergy to transfer the left resources to landfills in the best case. Here, $E_{c}^{\prime}=0$.

The equation of the minimum emergy recyclability can be calculated as follows:

$E_{\min }=E_{r}^{\prime \prime}-E_{c}^{\prime \prime}$

where $E_{r}^{\prime \prime}$ represents the recycled resource emergy in the worst case; $E_{c}^{\prime \prime}$ represents the consumption emergy paid for transferring the left resources to landfills in the worst case. Here, $E_{r}^{\prime \prime}=0$.

The equation of the actual emergy recyclability can be calculated as follows:
$E_{a}=E_{r}-E_{c}$

where $E_{r}$ represents the recycled resource emergy in the actual scenario. $E_{c}$ represents the consumption emergy paid for transferring the left resources.

\subsection{Case study}

The Green Eco-Manufacturer ELV recycling enterprise selected for this case study has been in operation since 2010 and is located in the circular economy industry park in Fengcheng County of Jiangxi Province, China. The area has a subtropical continental monsoon climate with annual mean temperature of $15.3-17.7^{\circ} \mathrm{C}$ and precipitation of $1543.5 \mathrm{~mm}$. As an ecological waste recycling plant, the enterprise is designed according to the advanced level of the world with the concept of "limited resources, unlimited circulation", covering an area of $333,333 \mathrm{~m}^{2}$.

The detailed operational flowchart of the ELV recycling procedure was shown in Fig. 3. The enterprise adopted the principle of dry green recycle to achieve the classified recycling of ELVs. With independent development technologies, the enterprise dismantled, crushed and separated ELVs to accomplish the efficient separation between metals and non-metals as well as between metals. According to Fig. 3, the first step of dismantling ELVs in the recycling enterprise was pretreatments, that is, to dismantle batteries and tires. Then hazardous parts, waste fluid (including motor oil, power steering fluid, transmission fluid, windshield washer fluid, gasoline, antifreeze and brake fluid), exterior parts, interior parts and assemblies were dismantled in sequence on the movable disassembly platform. After dismantling, the rest of the ELVs were cut into blocks which would be convenient for transportation. Then the scrap blocks were delivered to shredders and ground into metals of different sizes. At last, after magnetic separation and then eddy current separation, different usable materials were separated for sale and the automotive shredder residue (ASR) was transported to the landfill.

\subsection{Emergy evaluation procedure}

The first step of emergy accounting is to construct an energy flow diagram of the target system to identify all aspects, including their relationships and categories. A system's diagram is constructed with the symbols used in the energy language of systems ecology, so that a graphic representation of emergy sources and flows, system components and the circulation of money through 


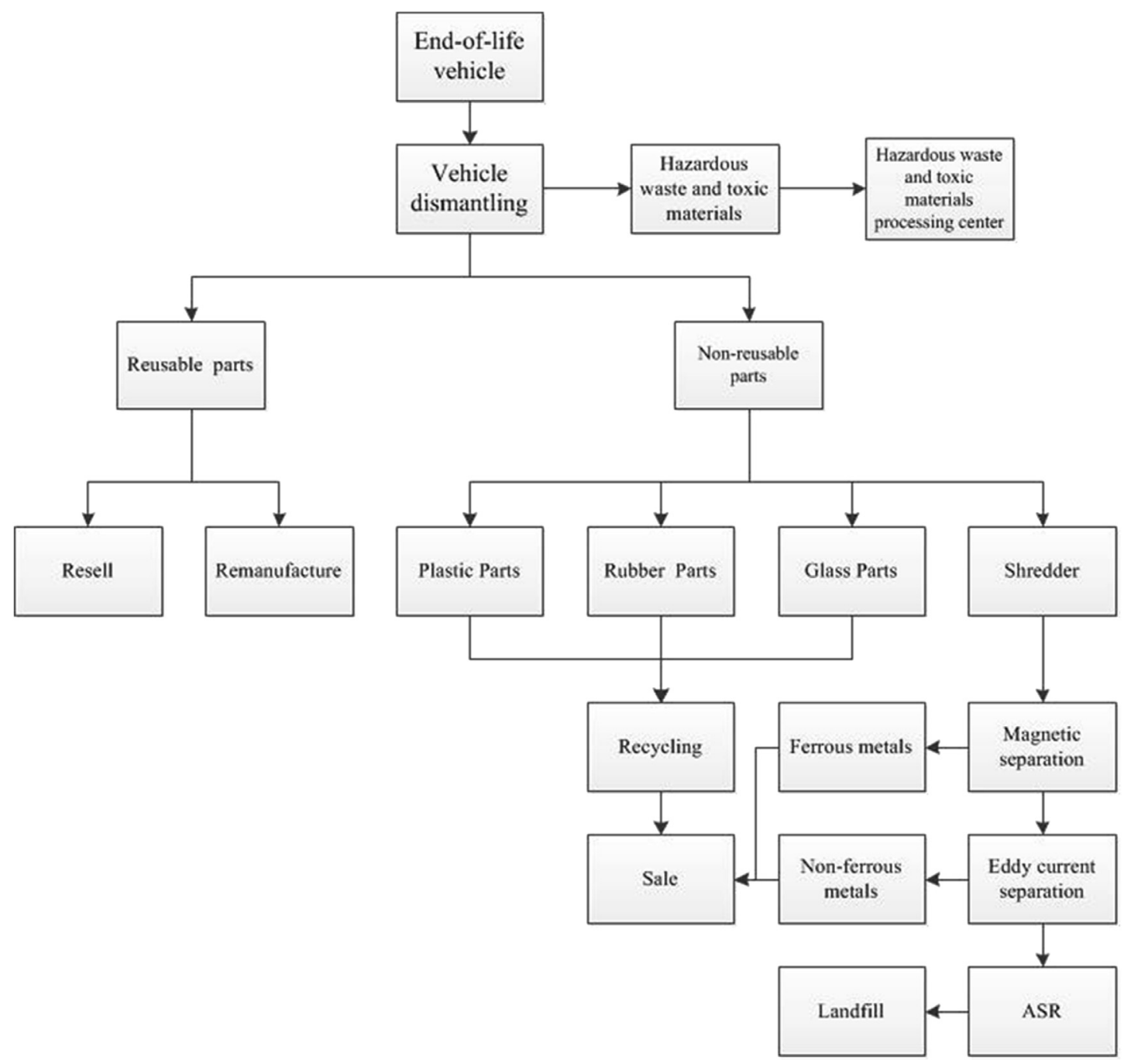

Fig. 3. Detailed operational flowchart of the ELV recycling procedure.

the system can be shown intuitively (Odum, 1996). The energy flow diagram of the ELV recycling system was shown in Fig. 2.

The second step is to organize different inputs in emergy evaluation tables and to calculate the emergy value of each input by multiplying the raw data of each input by transformity factors.

The third step is to aggregate all emergy flows and to analyze the structure of emergy inputs to a system. Finally, various emergybased indicators, including emergy density, emergy economic efficiency, emergy technical efficiency, emergy environmental efficiency and emergy sustainability of the studied system are calculated.

\section{Results and discussion}

\subsection{Emergy-based accounting}

The typical spread sheets for emergy accounting of the ELV recycling enterprise were listed in Table 2 , in which quantities of equivalent emergy values were categorized into five groups including renewable emergy inputs, emergy inputs from the economic system, non-renewable emergy inputs, waste emergy and output emergy. Global emergy baseline applied in this study was 15.83 E+24 sej/yr (Brown and Ulgiati, 2010; Odum et al., 2000).

\subsubsection{Renewable and non-renewable resources}

The renewable resource emergy input $(1.39 \mathrm{E}+17 \mathrm{sej} / \mathrm{yr})$ of the ELV recycling system accounted for merely $0.021 \%$ of all emergy inputs (excluding waste emergy $E_{w}$ ). As an industrial system, the ELV recycling system used less natural renewable resources than a natural system did. This low percentage is in accordance with expectation since the studied system was relatively a more technology-intensive industrial system compared to natural ecosystems.

As for the non-renewable resource input in ELV recycling enterprise, it mainly consisted of electricity and raw materials (ELVs). Since the enterprise had superior mechanized and semi-automated recycling process, electricity used for mechanical operations and office activities was the dominant energy resources flowing into the system. Making up $93.98 \%$ of the total emergy input, the raw material emergy $(6.25 \mathrm{E}+20 \mathrm{sej} / \mathrm{yr})$ was the most important nonrenewable resource emergy.

\subsubsection{Input from the economy}

In this study, inputs from the economic system were made up of management costs, labor costs, maintenance costs, research costs, selling costs, depreciation and other costs. The selling costs were mainly used for advertising and transportation, accounting for $26.95 \%$ of all economic emergy inputs. Comparing with the 
Table 2

Emergy synthesis table of the ELV recycling enterprise in China.

\begin{tabular}{|c|c|c|c|c|c|c|}
\hline Note & Item & Unit & Initial data & Transformity (sej/unit) & Reference & Solar emergy (sej/yr) \\
\hline \multicolumn{7}{|c|}{ Renewable inputs } \\
\hline 1 & Sun & $\mathrm{J} / \mathrm{yr}$ & $1.51 \mathrm{E}+15$ & 1 & By definition & $1.51 \mathrm{E}+15$ \\
\hline 2 & Wind & $\mathrm{J} / \mathrm{yr}$ & $1.46 \mathrm{E}+12$ & $2.51 \mathrm{E}+03$ & Odum et al. (2000) & $3.66 \mathrm{E}+15$ \\
\hline 3 & Rain (geopotential) & $\mathrm{J} / \mathrm{yr}$ & $2.27 \mathrm{E}+11$ & $1.76 \mathrm{E}+04$ & Odum et al. (2000) & $4.00 \mathrm{E}+15$ \\
\hline 4 & Rain (chemical) & $\mathrm{J} / \mathrm{yr}$ & $2.54 \mathrm{E}+12$ & $3.50 \mathrm{E}+04$ & Odum et al. (2000) & $8.89 \mathrm{E}+16$ \\
\hline 5 & Geothermal heat & $\mathrm{J} / \mathrm{yr}$ & $6.83 \mathrm{E}+11$ & $5.80 \mathrm{E}+04$ & Odum et al. (2000) & $3.96 \mathrm{E}+16$ \\
\hline 6 & Water & $\mathrm{g} / \mathrm{yr}$ & $2.11 \mathrm{E}+10$ & $4.80 \mathrm{E}+04$ & Odum et al. (2000) & $1.01 \mathrm{E}+15$ \\
\hline \multicolumn{7}{|c|}{ Non-renewable inputs } \\
\hline 7 & Electricity & $\mathrm{J} / \mathrm{yr}$ & $3.03 E+13$ & $2.00 \mathrm{E}+05$ & Odum (1996) & $6.06 \mathrm{E}+18$ \\
\hline 8 & Raw material & $\mathrm{g} / \mathrm{yr}$ & $5.00 \mathrm{E}+10$ & $1.25 \mathrm{E}+10$ & Yan (2001) & $6.25 \mathrm{E}+20$ \\
\hline \multicolumn{7}{|c|}{ Inputs from economy } \\
\hline 9 & Management costs & $\$ / y r$ & $1.01 \mathrm{E}+05$ & $4.90 \mathrm{E}+12$ & Jiang et al. (2008) & $4.95 \mathrm{E}+17$ \\
\hline 10 & Labor & $\$ / y r$ & $6.84 \mathrm{E}+05$ & $4.90 \mathrm{E}+12$ & Jiang et al. (2008) & $3.35 \mathrm{E}+18$ \\
\hline 11 & Maintenance costs & $\$ / y r$ & $1.32 \mathrm{E}+05$ & $4.90 \mathrm{E}+12$ & Jiang et al. (2008) & $6.47 \mathrm{E}+17$ \\
\hline 12 & Depreciation & $\$ / y r$ & $4.73 \mathrm{E}+05$ & $4.90 \mathrm{E}+12$ & Jiang et al. (2008) & $2.32 \mathrm{E}+18$ \\
\hline 13 & Research costs & $\$ / y r$ & $9.45 \mathrm{E}+05$ & $4.90 \mathrm{E}+12$ & Jiang et al. (2008) & $4.63 \mathrm{E}+18$ \\
\hline 14 & Selling costs & $\$ / y r$ & $9.45 \mathrm{E}+05$ & $4.90 \mathrm{E}+12$ & Jiang et al. (2008) & $5.93 \mathrm{E}+18$ \\
\hline 15 & Other costs & $\$ / y r$ & $1.21 \mathrm{E}+06$ & $4.90 \mathrm{E}+12$ & Jiang et al. (2008) & $4.63 \mathrm{E}+18$ \\
\hline 16 & Waste & See 1 & & & & $5.99 \mathrm{E}+18$ \\
\hline \multicolumn{7}{|c|}{ Output } \\
\hline 17 & Steel & $\mathrm{g} / \mathrm{yr}$ & $3.15 \mathrm{E}+10$ & $3.16 \mathrm{E}+09$ & Bargigli and Ulgiati (2003) & $9.95 \mathrm{E}+19$ \\
\hline 18 & Copper & $\mathrm{g} / \mathrm{yr}$ & $1.00 \mathrm{E}+09$ & $3.36 \mathrm{E}+09$ & Rugani and Benetto (2012) & $3.36 \mathrm{E}+18$ \\
\hline 19 & Aluminum & $\mathrm{g} / \mathrm{yr}$ & $4.00 \mathrm{E}+09$ & $1.44 \mathrm{E}+09$ & Odum (1996); Yan (2001) & $5.76 \mathrm{E}+18$ \\
\hline 20 & Glass & $\mathrm{g} / \mathrm{yr}$ & $1.50 \mathrm{E}+09$ & $2.77 \mathrm{E}+09$ & (Brown and Ulgiati, 2001) & $4.16 \mathrm{E}+18$ \\
\hline 21 & Plastic & $\mathrm{g} / \mathrm{yr}$ & $5.00 \mathrm{E}+09$ & $9.68 \mathrm{E}+09$ & Zhe et al. (2016) & $4.84 \mathrm{E}+19$ \\
\hline 22 & Rubber & $\mathrm{g} / \mathrm{yr}$ & $5.00 \mathrm{E}+09$ & $5.38 \mathrm{E}+09$ & Li and Wang (2009) & $2.69 \mathrm{E}+19$ \\
\hline
\end{tabular}

international advanced level, the technical level of the ELV recycling systems in China is still quite low, as a result, costs for research and development were still one of the most important economic emergy inputs, accounting for $21.05 \%$ of all economic emergy inputs. The emergy inputs of buildings and machinery were calculated into the costs of depreciation. The rest inputs from the outside economic system were mainly costs paid for the labor and services.

\subsubsection{Waste emergy}

In a natural ecosystem, natural wastes always end with inputs of another natural process. Furthermore, these wastes are usually the food for another kind of life form such as microorganisms. Therefore, waste emergy is generally not taken into consideration in a natural ecological system. However, in an industrial system, where no waste decomposition process existed and waste management is an indispensable obligation for enterprises, the waste emergy produced in industrial processes must be taken into consideration while emergy evaluation is taken.

According to Table 3, the waste produced by the ELV recycling enterprise could be divided into seven categories. The waste emergy of storage batteries contributed the largest waste emergy proportion, accounting for $42.56 \%$ of the total waste emergy, followed by waste emergy of sewage sludge (as much as $25.54 \%$ of the total waste emergy). Due to the ancillary sewage treatment facility and cyclic utilization of water, the wastewater was mainly made up by domestic wastewater and no industrial wastewater was discharged, resulting in little wastewater emergy (accounting for
$0.02 \%$ of the total waste emergy). The emergy of the other hazardous waste (including refrigerant, exhaust purifying catalyst, brake fluid, antifreeze and antidetonator) meant the emergy of services for disposing these wastes.

\subsubsection{Output emergy}

As shown in Table 2, there were approximately 5 categories of output products in the ELV recycling enterprise. The emergy of steel contributed the most to the output emergy (as much as 52.90\%). Plastic emergy also played an important role in the output emergy, and their emergy was $4.84 \mathrm{E}+19 \mathrm{sej} / \mathrm{yr}$, accounting for $25.73 \%$ of the total output emergy. Rubber emergy was $2.69 \mathrm{E}+19 \mathrm{sej} / \mathrm{yr}$, accounting for $14.30 \%$ of the total output emergy, followed in decreasing order by aluminum, glass and copper, each of which took up less than $3 \%$ of the total output emergy.

\subsection{Emergy indices}

Based on the emergy accounting for the ELV recycling enterprise, a number of emergy indices were calculated to evaluate the environmental performance and sustainability of the enterprise. According to Tables 4 and 5, there were mainly five categories of indices: emergy density, emergy environmental efficiency index, emergy economic efficiency index, emergy technical efficiency indices and emergy sustainability index, which all together present better insights into the economic structure, the sustainability and efficiency of the ELV recycling enterprise.

Table 3

Waste emergy of the ELV recycling enterprise in China.

\begin{tabular}{|c|c|c|c|c|c|}
\hline Waste category & Units & Initial data & Transformity (sej/unit) & Solar emergy (sej/yr) & Percentage \\
\hline 1. Brake fluid, antifreeze and antidetonator & $\$ / y r$ & $2.60 \mathrm{E}+04$ & $4.90 \mathrm{E}+12$ & $1.27 \mathrm{E}+17$ & $2.12 \%$ \\
\hline 2. Refrigerant & $\$ / \mathrm{yr}$ & $1.56 \mathrm{E}+05$ & $4.90 \mathrm{E}+12$ & $7.64 \mathrm{E}+17$ & $12.75 \%$ \\
\hline 3. Sewage sludge & $\$ / \mathrm{yr}$ & $3.12 \mathrm{E}+05$ & $4.90 \mathrm{E}+12$ & $1.53 \mathrm{E}+18$ & $25.54 \%$ \\
\hline 4. Storage battery & $\$ / \mathrm{yr}$ & $5.20 \mathrm{E}+05$ & $4.90 \mathrm{E}+12$ & $2.55 \mathrm{E}+18$ & $42.56 \%$ \\
\hline 5. Exhaust purifying catalyst & $\$ / \mathrm{yr}$ & $1.30 \mathrm{E}+05$ & $4.90 \mathrm{E}+12$ & $6.37 \mathrm{E}+17$ & $10.63 \%$ \\
\hline 6. Wastewater & $\$ / \mathrm{yr}$ & $1.98 \mathrm{E}+02$ & $4.90 \mathrm{E}+12$ & $9.70 \mathrm{E}+14$ & $0.02 \%$ \\
\hline 7. Other waste & $\$ / \mathrm{yr}$ & $7.80 \mathrm{E}+04$ & $4.90 \mathrm{E}+12$ & $3.82 \mathrm{E}+17$ & $6.38 \%$ \\
\hline
\end{tabular}


Table 4

Emergy indices of the ELV recycling enterprise in China.

\begin{tabular}{lll}
\hline Indices & & Value \\
\hline Renewable resources & & $\mathrm{R}=1.39 \mathrm{E}+17$ \\
Non-renewable inputs & & $\mathrm{N}=6.31 \mathrm{E}+20$ \\
Input from economy & & $\mathrm{F}=2.20 \mathrm{E}+19$ \\
Waste emergy & & $\mathrm{E}_{\mathrm{w}}=5.99 \mathrm{E}+18$ \\
End-of-life vehicle emergy & & $\mathrm{E}_{\mathrm{e}}=6.25 \mathrm{E}+20$ \\
Recycled resource emergy & & $\mathrm{E}_{\mathrm{r}}=1.88 \mathrm{E}+20$ \\
\hline & Traditional emergy & $\mathrm{Revised}$ emergy \\
& indices & indices \\
\hline Total emergy & $\mathrm{U}=6.53 \mathrm{E}+20$ & $\mathrm{U}_{\mathrm{r}}=6.59 \mathrm{E}+20$ \\
Emergy density & $\mathrm{ED}=1.96 \mathrm{E}+15$ & $\mathrm{ED}_{\mathrm{r}}=1.98 \mathrm{E}+15$ \\
Emergy economic efficiency & $\mathrm{EYR}=29.68$ & $\mathrm{EYR}_{\mathrm{r}}=23.54$ \\
$\quad$ indices & & \\
Emergy environmental & $\mathrm{ELR}=4697.84$ & $\mathrm{ELR}_{\mathrm{r}}=3.50$ \\
$\quad$ efficiency indices & & \\
Emergy sustainability index & $\mathrm{ESI}=0.0063$ & $\mathrm{ESI}_{\mathrm{r}}=6.73$ \\
\hline
\end{tabular}

Table 5

Emergy technical efficiency indices of the ELV recycling enterprise in China.

\begin{tabular}{lll}
\hline Indices & Expression & Value \\
\hline ERR & $\mathrm{E}_{\mathrm{r}} / \mathrm{E}_{\mathrm{e}}$ & $30.08 \%$ \\
$\mathrm{E}_{\min }$ & $\mathrm{E}_{\mathrm{r}}^{\prime}-\mathrm{E}_{\mathrm{c}}^{\prime}$ & $-3.62 \mathrm{E}+19$ \\
$\mathrm{E}_{\operatorname{maz}}$ & $\mathrm{E}_{\mathrm{r}}^{\prime \prime}-\mathrm{E}_{\mathrm{c}}^{\prime \prime}$ & $6.25 \mathrm{E}+20$ \\
$\mathrm{QER}$ & $\left(\mathrm{E}_{\mathrm{a}}-\mathrm{E}_{\min }\right) /\left(\mathrm{E}_{\max }-\mathrm{E}_{\min }\right)$ & $33.91 \%$ \\
\hline
\end{tabular}

\subsubsection{Emergy density}

The emergy density refers to the amount of input emergy flowing into one unit of area for development or a specific production process (in units of $\mathrm{sej} / \mathrm{m}^{2}$ ). The emergy density may suggest land as one of the limiting factors for the specific process or, in other words, may imply the necessity of a certain amount of support area for the system to be sustainable (Brown and Ulgiati, 2004b).

According to Table 4, without respect to the emergy required for waste treatment, the emergy density was $1.96 \mathrm{E}+15 \mathrm{sej} / \mathrm{m}^{2}$. While the revised emergy density, calculated with waste processing emergy, was $1.98 \mathrm{E}+15 \mathrm{sej} / \mathrm{m}^{2}$. Since more emergy would flow into the system per unit of time than that would be in the case using traditional indices, the revised emergy density was slightly higher than the traditional emergy density which excluded waste emergy. The emergy density of the ELV recycling enterprise was much higher than the national average of $5.40 \mathrm{E}+12 \mathrm{sej} / \mathrm{m}^{2}$ (NEAD, 2009), indicating that the ELV recycling enterprise consumed a large amount of emergy resources on a relatively small available area because of its highly concentrated population and technologies.

\subsubsection{Emergy economic efficiency indices}

Emergy Yield Ratio (EYR) measures the net contribution of a system to the main economy beyond its own costs and operation (Odum, 1996). In an industrial system, it represents the capability of the industrial system to exploit available local resources. It should be noted that EYR assesses the ratio of the system's output emergy flows and imported emergy flows, revealing the level of competitive strength and economic benefits of the system derived from a resource (Song et al., 2012). Low EYR values imply low competitiveness and poor economic benefits derived from a resource. Conversely, high EYR values imply strong competitiveness and high economic benefits.

As shown in Table 4, the revised Emergy Yield Ratio EYR $\mathrm{E}_{\mathrm{r}}$ was 23.54, which was smaller than the traditional EYR (29.68). Since the $E \mathrm{R}_{\mathrm{r}}$ of the ELV recycling enterprise was much larger than 5, according to Ulgiati and Brown (2002), the enterprise had strong competitive ability and high economic benefit, conforming to the actual conditions of the enterprise, which had a high profitability in 2013.

On the other hand, compared with the traditional EYR, the decreased $\mathrm{EYR}_{\mathrm{r}}$ indicated that due to the consideration of waste treatment, the competitive ability and economic benefit of the ELV recycling enterprise declined. Allowing for the labor, service and material resources purchased in the waste treatment processing, the decreasing EYR $\mathrm{r}_{\mathrm{r}}$ and subsequent lower economic benefits were unavoidable, and that's why lots of enterprises who only care about economic benefits do nothing in response to the appeal for cleaner production.

\subsubsection{Emergy environmental efficiency indices}

According to Cao and Feng (2007), if ELR is low (close to 2), then there is low environmental impact, and the process has a large area for the dilution of the total impact; if $10>$ ELR $>3$, the environmental impact is moderate, and if ELR $>10$, the environmental loading is high. For an extremely high value of ELR, the nonrenewable inputs or purchased inputs predominate. Therefore, in systems with high emissions or high nonrenewable resource consumption, high values of ELR are inevitable.

As shown in Table 4, the traditional Environmental Loading Ratio (ELR) was extremely high (4697.84) due to the low inflow of renewable resources to the ELV recycling process, indicating that local renewable resource inputs were far from enough for the demands of the process. However, the ELV recycling process was beneficial for both environment and human health and the emergy of its products could be regarded as a kind of renewable resource emergy. Therefore, to better evaluate the environmental efficiency of the ELV recycling process, a revision of the traditional index was essential.

According to Table 4, the revised ELR $\mathrm{r}_{\mathrm{r}}$ was 3.50, which was just a little larger than 3, indicating the ELV recycling enterprise had a moderate environmental impact. Compared with many other industrial systems, for instance, waste treatment systems (Winfrey and Tilley, 2016), steel production systems (Pan et al., 2015), polyethylene production processes (Mu et al., 2011) and sewage treatment systems (Zhang et al., 2015), the ELR $_{\mathrm{r}}$ of the end-of-life recycling system was much lower, which was in consistent with the nature of the system.

\subsubsection{Emergy sustainability index}

ESI provides an aggregated measure of the sustainability of a system. The definition of ESI is "the ratio of EYR to ELR", presenting the ability of a system to offer desired products and services with a maximum profit at the cost of the least environmental loading (Song et al., 2012). According to Cao and Feng (2007), a value of ESI less than 1 indicates that the system is unsustainable in the long run. If $1<\mathrm{ESI}<5$, the system may contribute sustainably to the economy for moderately long periods of time, and if $5<\mathrm{ESI}<10$, the system can be regarded as sustainable in the long run. If $10<\mathrm{ESI}$, the system is underdeveloped.

As shown in Table 4, the traditional emergy sustainability index was 0.0063 , which was far below 1, indicating that the ELV recycling enterprise cannot be kept sustainable in the long term. However, taken the reality of the enterprise into account, the adoption of the revised index was necessary. The revised ESI $_{\mathrm{r}}$ was 6.73 , indicating that the recycling system was both economically and environmentally sustainable in the long term. According to these results, the recycling enterprise had potential for development, and the sustainability of the enterprise was 117 times higher than a steel production system in China (0.057) (Pan et al., 2015), and 280 times higher than the average level of China's steel industry (Zhang et al., 2009). 


\subsubsection{Emergy technical efficiency indices}

According to Song et al. (2012), Emergy Recovery Ratio is a measure of the system's ability to recover materials and energy from the waste. Higher ERR values indicate more recovered emergy, and also a more advanced technology level with higher operating efficiency. As for QER, it allows for both the maximum emergy recyclability (equal to $E_{e}$ ) and the minimum recyclability, focusing on the concept of waste emergy.

According to Table 5, the ERR and the QER of the enterprise were $30.08 \%$ and $33.91 \%$, respectively, which were relatively low in comparison with the corresponding indices (ERR: 52.78\%; QER: $72.36 \%$ ) in a research on an e-waste treatment system by Song et al. (2013). Since the enterprise investigated in this study represented the leading enterprises of ELV recycling industry in China, the results suggested that, compared with the technical efficiency of the e-waste treatment industry, the technical level and operational efficiency of the ELV recycling industry in China were relatively low and more investment should be put into the improvement of the recycling technologies. Since the ELV recycling industry in China is still in the early stages of development, in contrast with ELV recycling enterprises in other developed countries, especially Japan, China's ELV recycling enterprises are generally lack of experience, professional equipment, management specifications and technologies, resulting in environmental pollution, low recycling rates and low dismantling efficiency (Zhao and Chen, 2011).

\section{Conclusions}

In this study, an emergy analysis with traditional and revised emergy indices was conducted to examine the efficiency and sustainability of ELV recycling systems. The Green Eco-Manufacturer ELV recycling enterprise, which is located in Fengcheng County in Jiangxi Province, was selected as the case-study for ELV recycling systems. Several distinct conclusions can be summarized as follows:

1) $93.98 \%$ of the total emergy input was from the raw material emergy $(6.25 \mathrm{E}+20 \mathrm{sej} / \mathrm{yr})$, which was the most important nonrenewable resource emergy. The emergy of steel contributed the most to the output emergy (as much as 52.90\%). As for the waste emergy, the waste emergy of storage battery, which accounted for $42.56 \%$ of the entire waste emergy, contributed the largest to the waste emergy.

2) As demonstrated by the EYR and ELR indices, the enterprise involved in the study had strong competitive ability with relatively high economic benefit $\left(\mathrm{EYR}_{\mathrm{r}}=23.54\right.$, large than 5$)$, and had a moderate environmental impact compared with other industrial systems $\left(10>\operatorname{ELR}_{\mathrm{r}}>3\right)$. The $\mathrm{ESI}_{\mathrm{r}}$ was 6.73 $(5<\mathrm{ESI}<10)$, indicated that the recycling system was both economically and environmentally sustainable in the long run.

3) According to the emergy technical efficiency indices, the technical level and operational efficiency of the ELV recycling enterprise were relatively low and more investment should be put into the improvement of the recycling technologies.

4) The improved energy indices could better reflect the actual characteristics of the system. Emergy evaluation indices should be built according to the specific characteristics of the different systems. Especially, the waste treatment emergy and recovery emergy from wastes should be given enough attention.

The case study showed the value of emergy analysis for evaluating the efficiency and sustainability of waste recycling systems. This revised efficiency and sustainability evaluation method based on emergy could reveal the value flowing into industrial systems from free environmental services and resources. Meanwhile, the emergy indices provide insight into the system's resource, environmental, economic and technological efficiency. Thus, it can be an important tool to help the decision makers to manage the enterprises, especially when the decisions need to be made regarding sustainability.

\section{Acknowledgments}

This work was sponsored by the Ministry of Science and Technology (2012BAC03B03-2) in China.

\section{Appendix A. Supplementary data}

Supplementary data related to this article can be found at http:// dx.doi.org/10.1016/j.jclepro.2016.05.045.

\section{References}

Bargigli, S., Ulgiati, S., 2003. Emergy and life-cycle assessment of steel production. In Biennial Emergy Evaluation and Research Conference, 2nd, Gainesville, Florida.

Brown, M.T., Ulgiati, S., 2001. A quantitative method for determining carrying capacity for economic investments. Int. J. Popul. Environ. 22, 13.

Brown, M.T., Ulgiati, S., 2004a. Emergy analysis and environmental accounting. In: Cleveland, C. (Ed.), Encyclopedia of Energy. Academic Press, Elsevier, Oxford, UK, pp. 329-354.

Brown, M.T., Ulgiati, S., 2004b. Energy quality, emergy, and transformity: H.T Odum's contributions to quantifying and understanding systems. Ecol. Model. 178, 201-213.

Brown, M.T., Ulgiati, S., 2010. Updated evaluation of exergy and emergy driving the geobiosphere: a review and refinement of the emergy baseline. Ecol. Model. 221, 2501-2508.

Buonocore, E., Vanoli, L., Carotenuto, A., Ulgiati, S., 2015. Integrating life cycle assessment and emergy synthesis for the evaluation of a dry steam geothermal power plant in Italy. Energy 86.

Cao, K., Feng, X., 2007. Distribution of emergy indices and its application. Energy Fuels 21, 1717-1723.

Chun-rong, J., Jun, Z., You-long, Z., Tie-Song, L., 2010. Emergy analysis of cassava -based fuel ethanol in China. In: Environmental Science and Information Application Technology (ESIAT), 2010 International Conference on, pp. 486-488.

Gungor, A., Gupta, S.M., 1997. An evaluation methodology for disassembly processes. Comput. Ind. Eng. 33, 329-332.

Hu, S., Kurasaka, H., 2013. Projection of end-of-life vehicle (ELV) population at provincial level of China and analysis on the gap between the future requirements and the current situation of ELV treatment in China. J. Mater. Cycles Waste Manag. 15, 154-170.

Hu, S., Wen, Z., 2015. Why does the informal sector of end-of-life vehicle treatment thrive? A case study of China and lessons for developing countries in motorization process. Resour. Conserv. Recycl. 95, 91-99.

Huisman, J., 2003. The QWERTY/EE Concept, Quantifying Recyclability and EcoEfficiency for End-of-Life Treatment of Consumer Electronic Products. Delft University of Technology.

Hwa-Cho, Y., Young-Chan, P., Kun-Sang, L., 2003. A study on the method of disassembly time evaluation of a product using work factor method. In: Systems, Man and Cybernetics, 2003. IEEE International Conference on, vol. 1752 pp. $1753-1759$.

Jiang, M.M., Zhou, J.B., Chen, B., Chen, G.Q., 2008. Emergy-based ecological account for the Chinese economy in 2004. Commun. Nonlinear Sci. Numer. Simul. 13, 2337-2356.

Kroll, E., Hanft, T., 1998. Quantitative evaluation of product disassembly for recycling. Res. Eng. Des. 10, 1-14.

Lee, S.G., Lye, S.W., Khoo, M.K., 2001. A multi-objective methodology for evaluating product end-of-life options and disassembly. Int. J. Adv. Manuf. 18, 148-156.

Li, D., Wang, R., 2009. Hybrid Emergy-LCA (HEML) based metabolic evaluation of urban residential areas: the case of Beijing, China. Ecol. Complex. 6, 484-493.

Liu, G., Yang, Z., Chen, B., Ulgiati, S., 2014. Emergy-based dynamic mechanisms of urban development, resource consumption and environmental impacts. Ecol. Model. 271, 90-102.

Liu, G., Yang, Z., Chen, B., Zhang, J., Liu, X., Zhang, Y., Su, M., Ulgiati, S., 2015. Scenarios for sewage sludge reduction and reuse in clinker production towards regional eco-industrial development: a comparative emergy-based assessment. J. Clean. Prod. 103, 371-383.

Mok, H.S., Kim, H.J., Moon, K.S., 1997. Disassemblability of mechanical parts in automobile for recycling. Comput. Ind. Eng. 33, 621-624.

Mu, H., Feng, X., Chu, K.H., 2011. Improved emergy indices for the evaluation of industrial systems incorporating waste management. Ecol. Eng. 37, 335-342.

NEAD, 2009. National Environmental Accounting Database Center for Environmental Policy. University of Florida.

Nielsen, S.N., Bastianoni, S., 2007. A common framework for emergy and exergy based LCA in accordance with environ theory. Int. J. Ecodyn. 2, 170-185. 
Odum, H.T., 1988. Self-organization, transformity, and information. Science 242, $1132-1139$.

Odum, H.T., 1996. Environmental Accounting: Emergy and Environmental Decision Making. Wiley.

Odum, H.T., Brown, M.T., Brandt-Williams, S., 2000. Handbook of Emergy Evaluation Folio 1: Introduction and Global Budget. Center for Environmental Policy, University of Florida, Gainesville, p. 16.

Pan, H., Zhang, X., Wu, J., Zhang, Y., Lin, L., Yang, G., Deng, S., Li, L., Yu, X., Qi, H., Peng, H., 2015. Sustainability evaluation of a steel production system in China based on emergy. J. Clean. Prod. 112 (Part 2), 1498-1509.

Pang, M., Zhang, L., Ulgiati, S., Wang, C., 2015. Ecological impacts of small hydropower in China: insights from an emergy analysis of a case plant. Energy Policy $76,112-122$.

PRWEB, 2015. China End-of-Life Vehicle (ELV) and Dismantling Industry Report, 2014-2017. Beijing, p. 86.

Ren, J., Manzardo, A., Mazzi, A., Fedele, A., Scipioni, A., 2013. Emergy analysis and sustainability efficiency analysis of different crop-based biodiesel in life cycle perspective. Sci. World J. 12.

Rugani, B., Benetto, E., 2012. Improvements to emergy evaluations by using life cycle assessment. Environ. Sci. Technol. 46, 4701-4712.

Song, Q., Wang, Z., Li, J., 2013. Sustainability evaluation of e-waste treatment based on emergy analysis and the LCA method: a case study of a trial project in Macau. Ecol. Indic. 30, 138-147.

Song, Q., Wang, Z., Li, J., Duan, H., 2012. Sustainability evaluation of an e-waste treatment enterprise based on emergy analysis in China. Ecol. Eng. 42, 223-231.

Tian, J., Chen, M., 2014. Sustainable design for automotive products: dismantling and recycling of end-of-life vehicles. Waste Manag. 34, 458-467.

Ulgiati, S., Brown, M.T., 2002. Quantifying the environmental support for dilution and abatement of process emissions: the case of electricity production. J. Clean. Prod. 10, 335-348.

Wang, L., Chen, M., 2013. Policies and perspective on end-of-life vehicles in China. J. Clean. Prod. 44, 168-176.
Wang, X., Dadouma, A., Chen, Y., Sui, P., Gao, W., Jia, L., 2015. Sustainability evaluation of the large-scale pig farming system in North China: an emergy analysis based on life cycle assessment. J. Clean. Prod. 102, 144-164.

Winfrey, B.K., Tilley, D.R., 2016. An emergy-based treatment sustainability index for evaluating waste treatment systems. J. Clean. Prod. 112 (Part 5), 4485-4496.

Yan, M., 2001. Introduction to New Ecological Economics. Chinese Zhigong publisher.

Yang, H., Chen, L., Yan, Z., Wang, H., 2011. Emergy analysis of cassava-based fuel ethanol in China. Biomass Bioenergy 35, 581-589.

Yang, H., Li, Y., Shen, J., Hu, S., 2003. Evaluating waste treatment, recycle and reuse in industrial system: an application of the eMergy approach. Ecol. Model. 160,13-21.

Zhang, B., Chen, G.Q., Yang, Q., Chen, Z.M., Chen, B., Li, Z., 2011a. How to guide a sustainable industrial economy: emergy account for resources input of Chinese industry. Procedia Environ. Sci. 5, 51-59.

Zhang, L., Geng, Y., Dong, H., Zhong, Y., Fujita, T., Xue, B., Park, H.-s, 2016. Emergybased assessment on the brownfield redevelopment of one old industrial area: a case of Tiexi in China. J. Clean. Prod. 114, 150-159.

Zhang, X., Deng, S., Zhang, Y., Yang, G., Li, L., Qi, H., Xiao, H., Wu, J., Wang, Y., Shen, F., 2011b. Emergy evaluation of the impact of waste exchanges on the sustainability of industrial systems. Ecol. Eng. 37, 206-216.

Zhang, X., Jiang, W., Deng, S., Peng, K., 2009. Emergy evaluation of the sustainability of Chinese steel production during 1998-2004. J. Clean. Prod. 17, 1030-1038.

Zhang, X., Wei, Y., Pan, H., Xiao, H., Wu, J., Zhang, Y., 2015. The comparison of performances of a sewage treatment system before and after implementing the cleaner production measure. J. Clean. Prod. 91, 216-228.

Zhang, X.H., Deng, S., Jiang, W., Zhang, Y., Peng, H., Li, L., Yang, G., Li, Y., 2010. Emergy evaluation of the sustainability of two industrial systems based on wastes exchanges. Resour. Conserv. Recycl. 55, 182-195.

Zhao, Q., Chen, M., 2011. A comparison of ELV recycling system in China and Japan and China's strategies. Resour. Conserv. Recycl. 57, 15-21.

Zhe, L., Yong, G., Hung-Suck, P., Huijuan, D., Liang, D., Tsuyoshi, F., 2016. An emergybased hybrid method for assessing industrial symbiosis of an industrial park. J. Clean. Prod. 114, 132-140. 